\title{
Aux sources de la poétique de Théophile Gautier: la préface d'“Albertus"
}

Damiano De Pieri

\section{(2) OpenEdition}

1 Journals

Édition électronique

URL : http://journals.openedition.org/studifrancesi/280

DOI : 10.4000/studifrancesi.280

ISSN : 2421-5856

Éditeur

Rosenberg \& Sellier

\section{Édition imprimée}

Date de publication : 1 avril 2015

Pagination : $35-53$

ISSN : 0039-2944

\section{Référence électronique}

Damiano De Pieri, «Aux sources de la poétique de Théophile Gautier: la préface d"Albertus" », Studi

Francesi [En ligne], 175 (LIX | I) | 2015, mis en ligne le 01 avril 2016, consulté le 10 décembre 2020 URL : http://journals.openedition.org/studifrancesi/280; DOI : https://doi.org/10.4000/studifrancesi. 280

\section{(c) (i) (9)}

Studi Francesi è distribuita con Licenza Creative Commons Attribuzione - Non commerciale - Non opere derivate 4.0 Internazionale. 


\title{
Aux sources de la poétique de Théophile Gautier: la préface d'"Albertus"
}

\begin{abstract}
Théophile Gautier is known to be the founder of the "art for art's sake" literary theory which is mainly outlined, according to the critics, in the preface of the novel Mademoiselle de Maupin (1835). Actually the first statements on the autonomy of art and supremacy of beauty can be traced back to the preface of the collection of poems entitled Albertus (1832). First of all, this paper aims to analyse the above-mentioned text in order to both show the originality and independence of the poet early in his career, within a context dominated by Hugo's poetics, and to highlight the elements of its new aesthetic feeling; secondly, to relate this aesthetic to the further developments of Gautier's poetics, highly heterogeneous though sharing a specific attitude towards art and artistic creation, and in which the consolation that comes from art has a crucial role. This perspective, I will argue, may provide a more authentic interpretation of Gautier's poetry, so to move past the preconceptions about his works.
\end{abstract}

Au cours de la première moitié du XIX ${ }^{\mathrm{e}}$ siècle, la préface, ce paratexte liminaire d'une œuvre, devient le lieu privilégié d'un «combat» à la fois littéraire, poétique, esthétique, mais aussi éthique et politique, souvent mené par de jeunes écrivains partagés entre la nécessité d'une confrontation avec la tradition et la volonté de dépassement de cette même tradition ${ }^{1}$. Par ailleurs, l'époque romantique, avec sa charge d'innovation littéraire et de réflexion critique, associée souvent à de fortes personnalités, est parcourue par une série de combats, plus ou moins célèbres, conduits à «coups» de préfaces qui visent à établir, ou à rétablir, une sensibilité esthétique et une pratique poétique. À ce propos, même s'il est sans doute difficile de définir le degré de volonté et de conscience de l'auteur par rapport à la formulation de l'instance préfacielle ${ }^{2}$, et d'en dégager un principe solide de cohérence programmatique par rapport à l'œuvre qui va suivre, la préface auctoriale originale, qui a pour «fonction cardinale d'assurer au texte une bonne lecture» ${ }^{3}$, témoigne des idées de l'auteur sur son art et, le cas échéant, sur sa vie, et peut donc représenter les étapes de ses idées et annoncer son évolution esthétique et poétique.

Théophile Gautier, poète devenu célèbre pour son engagement dans la bataille romantique à côté de $\mathrm{Hugo}^{4}$, est un excellent connaisseur du pouvoir communicatif

(1) Pour un aperçu sur les rôles des préfaces au $\mathrm{XIX}^{\mathrm{e}}$ siècle nous renvoyons au numéro 295 de la «Revue des Sciences Humaines», 3/2009, intitulé Préfaces et manifestes du XIX siècle, textes réunis par J.-L. DiAz, et surtout aux deux articles de ce dernier: «Préfaces 1830: entre aversion, principe et happening» où il déclare la préface «site décisif: champ de bataille et champ de forces, lieu de jouissance, espace de subversion», p. 38; et «"Manifestes" romantiques», pp. 80-98.

(2) Nous utilisons la terminologie que Gérard Genette formule dans Seuils, Paris, Editions du
Seuil, coll. «Points», 1987.

(3) Ibid., p. 200.

(4) À la fin de sa vie Gautier rappellera avec bonheur et un peu de nostalgie ses premiers pas dans l'arène littéraire: «nous avons eu l'honneur d'être enrôlé dans ces jeunes bandes qui combattaient pour l'idéal, la poésie et la liberté de l'art, avec un enthousiasme, une bravoure et un dévouement qu'on ne connaît plus aujourd'hui», Histoire du Romantisme, Paris, Gallimard, 2011, p. 60; devenue presque mythique, la première représentation d'Hernani le 25 février 1830 qui vit la flamboyante 
que peut avoir une préface. En effet, dans son Histoire du Romantisme, le poète s'exprime à plusieurs reprises sur la préface à Cromwell de Victor Hugo - considérée à posteriori par la critique un véritable manifeste du drame et de l'esthétique romantique - en soulignant l'importance capitale de ce texte pour la jeune génération.

La préface de Cromwell rayonnait à nos yeux comme les Tables de la Loi sur le Sinaï, et ses arguments nous semblaient sans réplique 5 .

\section{Ou encore:}

La Bible chez les protestants, le Koran parmi les Islamistes ne sont pas l'objet d'une plus profonde vénération. C'était bien, en effet, pour nous le livre par excellence, le livre qui contenait la pure doctrine ${ }^{6}$.

Et la «jeunesse romantique», «pleine d'ardeur et fanatisée par la préface de Cromwell [...] s'offrit au maître qui l'accepta» ${ }^{7}$. Texte quasi-prescriptif, voire dogmatique $^{8}$, la préface de Cromwell exerça un ascendant fondamental sur la nouvelle génération de poètes dans laquelle Gautier faisait son apparition.

Une fois dans l'arène littéraire en tant que poète, après avoir renoncé à un avenir de peintre ${ }^{9}$, le jeune Gautier écrit bien trois préfaces dans les années qui vont de 1832 à 1835: celle d'Albertus ${ }^{10}$, son deuxième recueil poétique, celle du recueil de contes humoristiques Les Jeunes-France ${ }^{11}$, et, finalement, la plus connue, celle de Mademoiselle de Maupin ${ }^{12}$. Et à propos de la valeur accordée aux préfaces, dans la préface des Jeunes-France, d'une manière sûrement burlesque et railleuse, Gautier écrit:

Moi, pour mon compte [...], je ne lis que les préfaces et les tables, les dictionnaires et les catalogues. C'est une précieuse économie de temps et de fatigue: tout est là, les mots et les idées. La préface, c'est le germe; la table, c'est le fruit: je saute comme inutiles tous les feuillets intermédiaires ${ }^{13}$.

participation du jeune Gautier habillé avec son gilet rouge parmi les jeunes recrutés pour la claque à la faveur de la pièce, fut la soirée qui, selon les mots de Gautier lui-même, «décida de [sa] vie!», ibid., p. 134. Les témoignages rapportés par Gautier dans son Histoire du Romantisme qui vont de ses rapports personnels à ses idées en passant par les évènements qui ont marqué son expérience, même s'ils risquent de proposer une autocélébration partielle et arbitraire du mouvement romantique, constituent une clé d'accès exceptionnelle pour interpréter sa vie et son œuvre.

(5) Ibid., p. 62.

(6) Ibid., p. 70.

(7) Ibid., p. 135.

(8) Notons banalement la récurrence de la comparaison de la préface aux textes religieux et la terminologie associée.

(9) En 1829 Gautier entre en apprentissage chez l'atelier du peintre Rioult et il y restera jusqu'en 1830 (cf. M. CERMAKIAN, Les années d'apprentissage de Théophile Gautier: peintre ou poète?, «Bulletin de la Société Théophile Gautier», n. 4, 1982). D'ailleurs cette vocation incertaine n'est pas sans effets, comme nous verrons, sur ses aspirations esthétiques futures, surtout pour ce qui concerne son désir d'atteindre à travers la poésie un idéal de beauté plastique. Et le sentiment d'un art supérieur à la nature qui anime Gautier remonte déjà à ces expériences artistiques si l'on croit aux affirmations contenues dans son «autoportrait», paru dans L'Illustration le 9 mars 1867, où le poète écrit: «le premier modèle de femme ne me parut pas beau, et me désappointa singulièrement, tant l'art ajoute à la nature la plus parfaite. [...] d'après cette impression, j'ai toujours préféré la statue à la femme, et le marbre à la chair», Histoire du Romantisme cit., pp. 438-439.

(10) Albertus ou l'Âme et le Péché, Paris, Paulin, enregistré à la «Bibliographie de la France» le 10 novembre 1832, daté 1833 dans la millésime de la page de titre. La préface est datée octobre 1832 par Gautier lui-même.

(11) Jeunes-France, romans goguenards, Paris, Renduel, 1833.

(12) Mademoiselle de Maupin, Paris, Renduel, 1835.

(13) Romans, contes et nouvelles, tome I, édition établie sous la direction de P. LAubriEt, Paris, Gallimard, Bibliothèque de la Pléiade, 2002, pp. 13-14. 


\section{Et encore:}

La préface de l'auteur, c'est le post-scriptum d'une lettre de femme, sa pensée la plus chère: vous pouvez ne pas lire le reste ${ }^{14}$.

Ce texte, qu'on pourrait définir comme une «méta-préface» puisque, dans la première partie, il traite de l'importance du texte liminaire par rapport à l'œuvre qui le suit, sur un ton évidemment ironique et par des contenus parodiques ${ }^{15}$, témoigne néanmoins de l'opinion générale sur la fonction des préfaces et surtout de l'opinion de Gautier lui-même. Pour lui il s'agit d'un lieu traversé par les «idées» de l'auteur et qui présente donc potentiellement les éléments d'une poétique, et non pas un simple texte, souvent négligeable, d'introduction.

Mais Gautier est surtout entré dans la postérité pour avoir écrit la préface à Mademoiselle de Maupin, considérée comme le manifeste de la doctrine de l'art pour l'art - malgré son auteur probablement. D'ailleurs, Gautier se méfiait de l'attitude didactique implicite dans la théorisation d'une véritable doctrine, et il était vraisemblablement loin de vouloir en établir une. Il suffit, en effet, de considérer certains de ses écrits plus «théoriques» pour s'en apercevoir. À notre connaissance, il ne nomme explicitement «l'art pour l'art» que dans l'article Du beau dans l'art paru dans la «Revue des Deux Mondes» le 1er septembre 1847 pour se défendre d'une interprétation inexacte de ce qu'il entend par cette formule. Pour le poète en effet elle ne renvoie pas à la «forme pour la forme», comme on a souvent affirmé, mais à un «travail dégagé de toute préoccupation autre que celle du beau lui-même» ${ }^{16}$.

La préface de Mademoiselle de Maupin suit de près la préface du recueil poétique Albertus, et les implications esthétiques qui y sont contenues, notamment l'inutilité de l'art, sont reprises de cette préface. Pourtant, le contexte à la base de l'origine des deux préfaces est très différent. Dans la préface à son roman Gautier voulait réaffirmer la liberté de l'art et se défendre en particulier contre les critiques littéraires du Constitutionnel qui l'avaient accusé d'immoralité à la suite de ses articles sur Théophile de Viau et Villon parus dans «La France littéraire» ${ }^{17}$. La préface à Albertus,

(14) Ibid., p. 14

(15) Cette tendance, à notre avis, a souvent nui à une pleine interprétation des textes de Gautier. En effet, le sarcasme domine dans le contexte des Jeunes-France (voir à ce propos l'étude de R. JASINSKI, Les années romantiques de Théophile Gautier, Paris, Vuibert, 1929). Ce sarcasme permettra à Gautier de garder toujours un regard plutôt détaché sur ses expériences littéraires, attitude qui si d'une part révèle la lucidité du poète et un fort esprit critique, d'autre part a poussé la critique à ne pas prendre trop au sérieux ses déclarations, soient elles directes, présentes dans ses textes plus au moins critiques, ou indirectes, dans son œuvre littéraire (aussi bien en prose qu'en poésie). Sur la dérision des excès romantiques et sur la démolition du «canon» préfaciel stéréotypé cf. L. VerCIANI, «L'antiromanticismo di un romantico: i JeunesFrance di Théophile Gautier», dans Tradizione e contestazione II. La manipolazione della forma nella letteratura francese dell'Ottocento, a cura di M.E. RAFFI, Firenze, Alinea editrice, 2009, pp. 99-113.

(16) «Revue des Deux Mondes», p. 900. En effet, Gautier se soucie peu des théorisations et des systématisations de son credo artistique et il gardera toujours une attitude créatrice, artisanale. Déjà en 1841 dans La Divine épopée, article sur l'œuvre d'Alexander Soumet qui annonce l'esthétique formaliste des Émaux et Camées paru dans la «Revue des Deux Mondes» le 1er avril, Gautier affirmait: «[1]'on a beaucoup agité, dans ces derniers temps, la question de la prééminence de la pensée sur la forme, l'on a beaucoup parlé du spiritualisme et du matérialisme, de la synthèse et de l'esthétique. Nous croyons que l'on s'est mépris sur la véritable portée de l'art; l'art, c'est la beauté, l'invention perpétuelle du détail, le choix des mots, le soin exquis de l'exécution; le mot poète veut dire littéralement faiseur; tout ce qui n'est pas bien fait n'existe pas», p. 121 .

(17) Pour l'histoire détaillée de l'origine de cette préface voir l'édition critique de G. Matoré, La préface de Mademoiselle de Maupin, Paris, Droz, 1946. D'ailleurs, toujours dans son autoportrait cité ci-dessus, Gautier parle de cette préface comme d'une attaque, intentionnelle, aux journalistes: «la préface souleva les journalistes, que j'y traitais fort mal. Nous regardions, en ce temps-là, les critiques comme des cuistres, des monstres, des eunuques et des champignons», Histoire du Romantisme cit., p. 441. 
par contre, n'est pas le résultat d'un événement anecdotique; elle est la préface d'un recueil poétique ${ }^{18}$ et se veut de présenter l'œuvre et la pensée du poète, dans un sens plus conforme à la tradition et à l'usage de la préface, plutôt que justifier son œuvre d'une manière polémique et colérique. Cependant, les critiques qui se sont occupés spécifiquement du recueil Albertus ont assez négligé la préface, tout en reconnaissant son rôle remarquable dans la formulation de la doctrine de l'art pour l'art et de la poétique de l'auteur ${ }^{19}$. Il nous semble donc intéressant de nous concentrer sur ce texte pour en faire une mise au point à la suite des différentes contributions et surtout pour essayer de l'interpréter à la lumière de l'évolution successive de l'œuvre de Gautier. En effet, cette préface vécue à l'ombre de la préface à Mademoiselle de Maupin, bien que rédigée dans la plus fébrile jeunesse du poète ${ }^{20}$, présente in nuce des innovations esthétiques qui seront successivement développées poétiquement par Gautier ainsi que par les poètes de la génération successive, et qui peuvent constituer un réseau de lignes interprétatives de sa poésie, trop souvent marquée par des préjugés et des stéréotypes.

La liberté de l'art professée par Hugo a joué un rôle important dans la formulation des idées esthétiques chez Gautier ${ }^{21}$. Liberté de l'art romantique par rapport aux règles du classicisme - mais aussi de n'importe quel «dogmatisme» - donc liberté esthétique, comme Hugo le revendique dans la préface à Cromwell: «La liberté de l'art contre le despotisme des systèmes, des codes et des règles» ${ }^{22}$. Mais liberté

(18) Il faudra attendre le recueil Émaux et Camées, Paris, Didier, 1852, pour avoir une autre préface de Gautier, cette fois une préface-poème dans la forme du sonnet.

(19) Celui qui a souligné les aspects distinctifs de cette préface, et qui est notre point de départ, est René JASINSKI qui en parle dans le chapitre consacré à Albertus des Années romantiques de Th. Gautier cit., pp. 93-95. Dans son introduction aux Poésies complètes de Théophile Gautier il affirme justement que la préface «établit dans toute sa pureté, sur un fond de pessimisme, la doctrine de l'art pour l'art», Paris Firmin-Didot, 1932, rééd. Paris, Nizet, 1970, p. XXIX (nous citons de l'édition Nizet). Plus récemment Jean-Pierre Saidah, en invitant justement à prendre au sérieux les propos du poète cachés sous sa pose humoristique, écrit que la préface «est déjà un manifeste de l'art pour l'art», $L e$ diable en babit dandy ou le triomphe du dandysme littéraire dans "Albertus", «Bulletin de la Société Théophile Gautier», n. 14, 1992, p. 26; William G. ALLEN dans son article «Gautier's Albertus: The fantastic and the fashionable», à propos d'Albertus affirme: «Since its first publication, Albertus has been recognized as a massively imitative work. Yet it must be noted as well that to an astonishing degree, Albertus announces the thematic, esthetic and literary concerns which will continue to occupy Gautier throughout his entire life: the metaphysical anguish which informs his fantastic narrative, the ironic narrative voice which characterizes many of his récits of the 1830's, the cult of ideal beauty, the notion of art for art's sake, the transpositions d'art or the intrusion of a strongly visual element into literature, and the cultivation of the concrete detail as a primary feature of writing», Correspondances: Studies in Literature, History, and the Arts in Nineteenth-Century France, éd. K. BusBy, Amsterdam,
Rodopi, 1992, p. 10. Enfin, Constance Gosselin SCHICK dans son étude sur l'œuvre poétique du poète Seductive Resistance: The Poetry of Théophile Gautier, analysant la préface d'une manière plus détaillée, conclut que ce texte «is [...] an important text, not simply as a convenient landmark or standard-bearer for Art-for-Art's Sake categorizations and definitions, but because it gives face or expression to the young Gautier's complex poetics which, with both humor and conviction, give consideration to poetry's importance and power in terms of aesthetics and social engagement», Amsterdam, Rodopi, 1994, p. 36.

(20) Gautier, né en 1811, n'avait à l'époque que 21 ans.

(21) Gautier d'ailleurs affirme que la rencontre avec Hugo fut déterminante pour sa décision de devenir écrivain. Dans son autoportrait il raconte: «Je demeurais $[\ldots]$ avec mes parents à la place Royale, n. 8, dans l'angle de la rangée d'arcades où se trouvait la mairie. Si je note ce détail, ce n'est pas pour indiquer à l'avenir une de mes demeures. [...] Mais cette circonstance influa beaucoup sur la direction de ma vie. Victor Hugo, quelque temps après la révolution de Juillet, était venu loger à la place Royale, au n. 6, dans la maison en retour d'équerre. On pouvait se parler d'une fenêtre à l'autre. J'avais été présenté à Hugo, rue Jean-Goujon, par Gérard [de Nerval] et Petrus Borel, le lycanthrope», p. 439; et encore: «Le voisinage de l'illustre chef romantique rendit mes relations avec lui et avec l'école naturellement plus fréquentes. Peu à peu je négligeai la peinture et me tournai vers les idées littéraires», Histoire du Romantisme cit., p. 441.

(22) «Préface» à Cromwell [1827], Théátre complet, préface par R. PuRnAL, notices et notes par J. J. ThIERRY et J. MélĖze, tome I, Paris, Gallimard, «Bibliothèque de la Pléiade», 1963, p. 444. 
surtout dans le sens d'autonomie de l'expression artistique, d'autosuffisance du fait artistique, comme le poète l'affirme dans les préfaces des Orientales et des Feuilles d'automne: «il n'y a, en poésie, ni bons ni mauvais sujets, mais de bons et de mauvais poètes ${ }^{23}$. Le poète doit donc être jugé selon sa capacité artistique, c'est-à-dire sur la manière dont il a travaillé et «non sur quoi et pour quoi» ${ }^{24}$ puisque «l'art a sa loi [...] comme le reste a la sienne» ${ }^{25}$. Par ailleurs, Hugo écrit ces recueils poétiques dans un moment d'effervescence et de combat qui n'est pas seulement esthétique, mais également politique et social ${ }^{26}$. À cet égard il faut rappeler que les poèmes des Orientales sont en bonne partie consacrés à la cause de l'indépendance de la Grèce et que les Feuilles d'automne sont écrites pendant une période tourmentée, après la Révolution des «Trois glorieuses». En effet, dans ces deux préfaces l'on entrevoit l'exigence, mais aussi la difficulté, de Hugo à maintenir parallèlement d'une part l'autonomie du poète et la liberté de l'art et d'autre part à ne pas couper complètement le lien qui unit la poésie et le poète aux évènements et, d'une manière presque empathique, à la condition humaine. Si la poésie est indépendante c'est à cause de son caractère d'universalité: grâce à la communication qu'elle assure avec l'intériorité de l'homme le poète ne renonce pas à son rôle actif dans la sociétée $e^{27}$. Dans une période tumultueuse le poète-artiste se voit donc contraint à repenser son statut et son rôle qui risquent d'être minés et éclipsés par les événements historiques. Il doit ainsi renouveler son rapport avec la société: se rallier au flux de l'histoire en participant activement aux changements en cours, ou se retirer complètement de ce flux pour (re)créer un espace où reconstituer son propre rôle, voire sa propre identité. C'est dans la tension entre ces deux possibilités que l'on assiste à l'émergence du «champ» littéraire autonome ${ }^{28}$. Entre ces deux positions il y a évidemment des nuances, comme on le voit clairement chez Hugo, imposées par l'exigence de garantir au poète et à son art son autonomie, sa liberté et sa dignité, pour éviter la subordination de l'art à la politique et aux pouvoirs dominants (social, politique, économique) ${ }^{29}$, et en même temps pour assurer au

(23) «Préface de l'édition originale», Les Orientales, Euvres poétiques, préface par G. PICON, édition établie et annotée par P. AlbOuY, «Avant l'exil, 1802-1851», tome I, Paris, Gallimard, «Bibliothèque de la Pléiade», 1964, p. 577.

(24) Ibid.

(25) «Préface», Les Feuilles d'automne, Euvres poétiques, tome I, p. 712.

(26) Autour des années de crises avant et après la Révolution de 1830 le thème de l'engagement des artistes est presque quotidien et la question esthétique est entremêlée aux préoccupations politiques et sociales. Les appels à rallier la cause sociale qui apparaissent dans les journaux de l'époque et dans des pamphlets sont nombreux: de Sainte-Beuve («Le Globe», 11 octobre 1830), aux politiques saint-simoniens Pierre Leroux (différents articles parus dans «Le Globe» et la «Revue encyclopédique») et Émile Barrault (Aux Artistes, Paris, Alexandre Mesnier Libraire, 1830). Et la querelle, plus esthétique que politique, entre la tradition de l'académie et les innovations du romantisme se prolonge au moins jusqu'à la moitié des années trente qui voient s'opposer Désiré NISARD (D'un commencement de réaction contre la littérature facile, «Revue de Paris», 1er décembre 1833) et Jules Janin (Manifeste de la jeune littérature, «Revue de Paris», 5 janvier 1834). Pour un bref aperçu sur ce contexte nous renvoyons aux notes de la préface des Feuilles d'automne, Euvres poétiques, tome I, cit., pp. 1332-1334; et pour ce qui concerne la naissance de l'art pour l'art à l'indispensable étude d'A. Cassagne, La Théorie de l'art pour l'art en France chez les derniers romantiques et les premiers réalistes, Paris, Hachette, 1906, rééd. Seyssel, Champ Vallon, 1997, mais aussi à l'article de J. GAUCHERON, Ombres et lueur de l'art pour l'art, «Europe», n. 601, 1979, qui donne, avec raison, une grande importance à la préface d'Albertus.

(27) «À l'adolescent elle parle de l'amour; au père, de la famille; au vieillard, du passé; et quoi qu'on fasse, quelles que soient les révolutions futures [...] il y aura toujours des enfants, des mères, des jeunes filles, des vieillards, des hommes enfin, qui aimeront, qui se réjouiront, qui souffriront. C'est à eux que va la poésie» écrit Hugo dans la préface aux Feuilles d'automne cit., p. 713; et à la fin, en parlant de soi à la troisième personne, il conclut qu'il «veut toute liberté, toute amélioration, tout progrès, et en même temps toute précaution, tout ménagement et toute mesure», p. 716.

(28) Sur la question historique et sociale du fait littéraire nous sommes redevable de l'analyse proposée par Pierre BouRdiEu dans Les règles de l'art. Genèse et structure du champ littéraire, Paris, Éditions du Seuil, 1992, dont nous utilisons la terminologie.

(29) Ce que Bourdieu appelle «subordination 
poète un rôle qui ne soit pas marginal. On sait que Hugo n'a jamais refusé et il ne refusera jamais une fonction «sociale» à la poésie ${ }^{30}$; au contraire, il refusera fermement d'avoir été un partisan de l'art pour l'art ou de l'avoir même inspiréé

La préface des Feuilles d'automne est reconnue par Jasinski comme la source directe de la préface d'Albertus même si le critique ajoute que la similitude est plutôt apparente. En effet, au-delà des liaisons intertextuelles qu'il décèle, les deux préfaces divergent considérablement en ce qui concerne la conception de l'art mais aussi de l'artiste-poète par rapport à la société ${ }^{32}$.

Si la préface de Gautier prolonge les propos de Hugo sur la liberté de l'art, ces derniers sont portés aux extrêmes conséquences et posent les bases pour une nouvelle poétique $e^{33}$. D'abord, la liberté et l'autonomie de l'art s'expriment à travers un refus total des préoccupations politiques: dans la préface d'Albertus la politique n'est pas seulement rejetée, elle est aussi méprisée. Si Hugo, dans Les Feuilles d'automne, définit les révolutions des «glorieux changements d'âge de l'humanité» ${ }^{34}$ et montre

structurale», accrue, à cause de la nature antilibérale du régime, pendant le Second Empire, cf. Les règles de l'art cit., pp. 86-95.

(30) Il suffit de lire les préfaces qui ont accompagné les Odes et Ballades pour s'en convaincre. Il écrit, par exemple, dans celle de 1824, que le poète «doit marcher devant les peuples comme une lumière et leur montrer le chemin», Euvres poétiques, tome I, cit., p. 277, anticipant le célèbre poème «Fonction du poète» du recueil Les Rayons et les Ombres.

(31) «Je n'ai jamais dit l'Art pour l'Art; j'ai toujours dit l'Art pour le Progrès. Au fond, c'est la même chose, et votre esprit est trop pénétrant pour ne pas le sentir. En avant c'est le mot du Progrès; c'est aussi le cri de l'Art. Tout le verbe de la Poésie est là. Ite. [...] Le poète ne peut aller seul, il faut que l'homme se déplace. Les pas de l'Humanité sont donc les pas même de l'Art. - Donc, gloire au Progrès», Lettre à Baudelaire, le 6 octobre 1859. En effet, cette lettre est écrite pour préfacer la brochure qui devait contenir l'étude de Baudelaire sur Théophile Gautier parue dans la revue «L'Artiste», Théophile Gautier, notice littéraire précédée d'une lettre de Victor Hugo, Paris, Poulet-Malassis, 1859, p. 11. La difficulté, voire l'impossibilité, de la position de Hugo est évidente dans la formule ambiguë qui résulte de cette lettre: l'art pour l'art est «la même chose» que l'art pour le progrès.

(32) «La préface est significative. Elle procède, à n'en pas douter, de la préface des Feuilles d'automne. On peut même juger trop exactes certaines concordances [...] Mais la ressemblance reste plus extérieure que profonde», Les années romantiques de Théophile Gautier cit., pp. 93-94. Dans l'édition critique des Poésies complètes, Jasinski écrit qu'audelà de cette préface, la préface de Gautier rappelle aussi celle des Orientales et celle du recueil poétique Poésies de Charles Dovalle écrite par Hugo même, op. cit., p. XXIX. Mais celle-ci, qui date de 1830, rédigée donc entre la préface des Orientales et celle des Feuilles d'automne, témoigne encore une fois le sentiment d'un rapport strict entre le destin social et historique et la littérature: «Le romantisme, tant de fois mal défini, n'est, à tout prendre, et c'est là sa définition réelle, que le libéralisme en littérature. [...] La liberté dans l'art, la liberté dans la société, voilà le double but auquel doivent tendre d'un même pas tous les esprits conséquents et logiques», Le Sylphe, Poésies de feu Ch. Dovalle, Paris, Ladvocat, 1830 , p. XII.

(33) Si nous étendons la question du rapport de filiation de la naissante esthétique exposée par Gautier au rapport que la doctrine générale de «l'art pour l'art» et son issue quasi-naturelle, le Parnasse, entretiennent avec le romantisme, la question devient problématique. Albert Cassagne (op. cit.) privilégie la continuité de cette doctrine avec le romantisme. Pareillement Pierre Martino parle du Parnasse comme d'une troisième génération de l'art pour l'art - dont la première est incarnée par Gautier - (cf. Parnasse et Symbolisme, Paris, Armand Colin, 1926, p. 65). Maurice Souriau opte pour la discontinuité violente entre romantisme et Parnasse et accorde à Gautier le rôle de l'«ancêtre», de celui qui le premier s'est détaché du romantisme (cf. Histoire du Parnasse, Paris, Spes, 1929, introduction et premier chapitre). Plus récemment Martine Lavaud considère que le Parnasse «se formait dans une région particulière du romantisme dont Gautier était le dernier survivant» (Théophile Gautier, militant du romantisme, Paris, Champion, 2001, p. 396). Affirmation diamétralement opposée à celle d'Yann Mortelette qui déclare dans son étude fondamentale sur le Parnasse que l'art pour l'art n'est pas une théorie romantique «ni le Parnasse un néo-romantisme» (Histoire du Parnasse, Paris, Fayard, 2005, p. 102). D'ailleurs, Gautier n'a-t-il subi une bonne quantité d'étiquettes: romantique, anti-romantique, parnassien, impassible, classique même? Sans vouloir trop schématiser nous préférons adopter la méthode interprétative suggérée par Carlo Pasi afin de chercher plutôt à identifier les constantes, les convergences et les divergences qui caractérisent la poétique de Gautier à mi-chemin entre les expériences romantiques et le Parnasse (cf. Il Sogno della materia, saggio su Théophile Gautier, Roma, Bulzoni, 1972, p. 19).

(34) «Préface», Les Feuilles d'automne, Euvres poétiques cit., p. 713. 
sa confiance dans l'action politique, Gautier, qui affirme sa «foi» apolitique - «il [l'auteur] n'a aucune couleur politique» ${ }^{35}$ - est ironique et négatif quant au pouvoir de changement accordé aux révolutions: le poète «ne s'aperçoit des révolutions que lorsque les balles cassent les vitres» ${ }^{36}$. Son œuvre est indépendante des questions politiques, il s'agit d'un œuvre «purement littéraire», «d'art et de fantaisie» ${ }^{37}$. Toutes les intentions du poète sont d'ordre purement esthétique et poétique:

Quant aux utilitaires, utopistes, économistes, saint-simonistes et autres qui lui demanderont à quoi cela rime, - il répondra: le premier vers rime avec le second quand la rime n'est pas mauvaise, et ainsi de suite.

À quoi cela sert-il? Cela sert à être beau. - N'est-ce pas assez? Comme les fleurs, comme les parfums, comme les oiseaux, comme tout ce que l'homme n'a pu détourner et dépraver à son usage ${ }^{38}$.

La conception idéale, insaisissable, floue du «beau», qui chez Gautier se définira de plus en plus comme une beauté plastique et formaliste, fait irruption dans la poésie au-delà des épanchements et des effusions lyriques et complètement affranchie des éléments exogènes de nature utilitariste:

En général, dès qu'une chose devient utile, elle cesse d'être belle. - Elle rentre dans la vie positive, de poésie elle devient prose, de libre esclave. - Tout l'art est là. - L'art, c'est la liberté, le luxe, l'efflorescence, c'est l'épanouissement de l'âme dans l'oisiveté. - La peinture, la sculpture, la musique ne servent absolument à rien" ${ }^{39}$.

Ces mots expriment parfaitement le concept de l'inutilité de l'art qui demeure à la base de l'art pour l'art: un art qui n'a d'autre but que celui de la beauté, puisque l'utilité de l'art compromet la beauté de l'art lui-même. Il ne faut pas utiliser l'art, le «dépraver à son usage». L'art ne peut pas être asservi aux «choses de la vie» ${ }^{40}$, parce que ces choses sont viles, sont prosaïques et n'ont rien à voir avec la Beauté, et sa haute noblesse ne peut pas être trahie même si «le vent ne souffle pas à la poésie» ${ }^{41}$.

(35) «Préface», Albertus, Poésies complètes cit., tome I, p. 81. (Dorénavant nous abrégeons Poésies complètes en P.C.)

(36) Ibid. Dans la préface aux Jeunes-France Gautier confirme son mépris et son désintérêt à travers le même ton ironique et à travers presque les mêmes mots: la révolution n'est que «des gens qui se tirent des coups de fusil dans la rue: cela casse beaucoup de carreaux; il n'y a guère que les vitriers qui y trouvent du profit», op. cit., p. 21. Et dans le sonnet-préface des Émaux et Camées le poète, toujours à propos d'une révolution, en ce cas celle de 1848, affirmera: «Sans prendre garde à l'ouragan | Qui fouettait mes vitres fermées, | Moi, j’ai fait Émaux et Camées», P.C., tome III, p. 3.

(37) «Préface», Albertus cit., p. 82.

(38) Ibid

(39) Ibid. Dans l'article intitulé «Modern Beauty versus Platonist Beauty», contenu dans Baudelaire and the poetics of modernity, edited by P.A. WARD, Vanderbilt University Press, Nashville, 2001, Michel Brix met en évidence la double tendance esthétique du romantisme qui d'une part, par l'influence du platonisme, cherche à unir le Vrai, le Beau et le Bien, de l'autre se borne à l'aspect sensoriel et terrestre. Mais l'idéal de perfection reste toujours hors de la portée du poète. Si Gautier révèlera à plusieurs reprises son penchant platonique pour la définition de la beauté (cf. Du Beau dans l'art, art. cit., et Plastique de la civilisation, «L'Événement», 8 août 1848), il est difficile d'imaginer qu'il en partage l'idéalisme d'une équivalence entre le Beau, le Vrai et le Bien - titre aussi de l'essai d'esthétique de Victor Cousin fondé sur le platonisme filtré par l'idéalisme allemand, notamment de Schelling. Chez Gautier le modèle de beauté est concret et sensoriel, terrestre, même si le poète aspire paradoxalement à un idéal, qu'il soit d'une perfection formelle insaisissable ou qu'il soit d'éternité; de toute manière, pour lui, la beauté reste indépendante du bien. Dans un discours rapporté par les Goncourt, ne parle-t-il pas de «corruption suprême» à propos du goût le plus raffiné de l'exotisme dans le temps, c'est-à-dire d'un modèle de beauté antique, classique et païenne? (cf. Journal des Goncourt, deuxième volume, 1862-1865, Paris, Charpentier, 1888 , p. 166)

(40) «Préface», Albertus cit., p. 81

(41) Ibid. 
Faire de l'art un véhicule de quelque chose d'autre signifierait le dégrader. Mais l'indifférence envers la politique est contrebalancée par l'attention que le poète porte sur son art, sa seule préoccupation étant de bien accomplir son travail poétique:

Pour les critiques d'art ou de grammaire qu'on pourra lui adresser, il y souscrit d'avance. - Il connaît très bien les défauts et les taches de son livre ${ }^{42}$.

\section{Ou encore:}

Si on lui répond: «Fort bien, - mais vos vers ne sont pas beaux», il passera condamnation et tachera de s'amender. - il espère toutefois qu'on voudra bien lui savoir gré de l'intention ${ }^{43}$.

L'insistance de Gautier sur l'inutilité de l'art, sur son autonomie, mais surtout sur son autosuffisance, l'attitude dédaigneuse envers les «choses de la vie» qui caractérise la figure du poète et la revendication d'une liberté totale, ayant toutefois l'impératif de rendre le «beau» à travers une bonne maîtrise de son art, souligne déjà la distance qui se creuse tout au début de la carrière poétique de Gautier entre celui-ci et son maître. En effet, il nous semble que si Gautier s'empare des idées en circulation sur la liberté de l'art et surtout des affirmations présentes dans les différentes préfaces de Hugo, il le fait pour mieux souligner sa diversité et pour mieux marquer une rupture, une discontinuité qui sera d'ailleurs confirmée par ses œuvres successives ${ }^{44}$. Dans cet espace textuel qui est la préface du jeune Gautier nous assistons donc à la constitution consciente de l'autonomie du champ littéraire et du poète, de Gautier lui-même, bien que l'élément assertif soit nuancé par le ton ironique, de défi et de provocation ${ }^{45}$ qui met en relief la pose étalée du poète plus que le contenu ${ }^{46}$.

La valeur suprême accordée à l'art et cette attitude exubérante remontent sans nul doute au contexte du Petit Cénacle de la jeune génération romantique où peintres, poètes et sculpteurs se consacraient fraternellement au culte de l'art et de la beauté ${ }^{47}$.

(42) Ibid., p. 82.

(43) Ibid., p. 83.

(44) À l'époque il y a évidemment un climat de frustration collective, dû à la déception provoquée par les échecs des révolutions qui se sont déroulées dans la première moitié du siècle et à la conscience amère de l'impossibilité du poète de gouverner les évènements historiques, qui caractérise surtout ceux que Bénichou a groupé sous le nom d'«école du désenchantement»: Sainte-Beuve, Nodier, Musset, Nerval et Gautier. Tous partagent un même sentiment de désillusion affronté de manière différente mais qui pousse le poète à se replier sur son art. Cette attitude, «négation de la politique et refuge dans la poésie, est assurément, et restera, le fond de Gautier», L'école du désenchantement, Paris, Gallimard, 1992, p. 502.

(45) L'auteur «ne craint pas de jeter entre deux émeutes, peut-être entre deux pestes, un volume purement littéraire», «Préface» à Albertus, P.C. cit., p. 82.

(46) Pierre Bourdieu accorde une importance capitale à l'art pour l'art en ce qui concerne la «conquête de l'autonomie» du champ littéraire: «les tenants de l'«art pur» vont beaucoup plus loin que leurs compagnons de route, en apparence plus radicaux: le détachement esthète, qui $[. .$.$] constitue le$ véritable principe de la révolution symbolique qu'ils opèrent, les conduit à rompre avec le conformisme moral de l'art bourgeois sans tomber dans cette autre forme de complaisance éthique qu'illustrent les tenants de l'«art social» et les «réalistes» [...] l'«art pour l'art» est une position à faire, dépourvue de tout équivalent dans le champ du pouvoir [...] Bien qu'elle soit inscrite à l'état potentiel dans l'espace même des positions déjà existantes et que certains des poètes romantiques en aient déjà dessiné l'exigence, ceux qui prétendent l'occuper ne peuvent la faire exister qu'en faisant le champ dans lequel elle pourrait trouver place, c'est-à-dire en révolutionnant un monde de l'art qui l'exclut, en fait et en droit. Ils doivent donc inventer, contre les positions établies et leurs occupants, tout ce qui la définit en propre, et d'abord ce personnage social sans précédent qu'est l'écrivain ou l'artiste moderne, professionnel à plein temps, voué à son travail de manière totale et exclusive, indifférent aux exigences de la politique et aux injonctions de la morale et ne reconnaissant aucune autre juridiction que la norme spécifique de son art», Les règles de l'art cit., pp. 130-132.

(47) Le Petit Cénacle, né aux marges du «grand» cénacle de Hugo et appelé ainsi par Gautier dans son Histoire du Romantisme (cf. pp. 68-83), était constitué par les écrivains Gérard de Nerval, Auguste Maquet, Philothée O’Neddy (pseudonyme de Théophile Dondey), Joseph Bouchardy, Théophile Gautier et Pétrus Borel, le sculpteur Jehan Du Seigneur, les peintres Napoléon Thomas et Célestin Nanteuil. 
La coprésence de différentes activités artistiques et l'échange fécond qui advint entre écrivains et artistes, à l'enseigne d'une idéale fraternité des arts, contribua chez Théophile Gautier au renouvellement de son langage poétique ${ }^{48}$. Et on peut affirmer que ce cénacle, bien qu'il ait eu peu de place dans l'histoire culturelle, représente l'une des premières expériences collectives modernes, où des artistes de différentes disciplines poursuivent un même idéal artistique associé à un style de vie commun (le dandysme, la bohème) même si cet idéal et l'idéologie qui le sous-tend, dans le sens le plus large du terme, ne sont pas codifiés de manière univoque et définitive dans des textes véritablement programmatiques, et même si les marges entre lesquelles ces «âmes artistes» ${ }^{49}$ s'orientent vers leur «rêve de beauté» sont plutôt variables $^{50}$. En effet, les jeunes snobs, provocateurs et contestataires qui fréquentent ce cénacle manifestent souvent la même exaltation pour l'art et le même mépris des «choses de la vie» ${ }^{51}$, mais dans ce groupe la politique n'est pas toujours fièrement et fidèlement récusée à la faveur de l'art comme chez Gautier. Petrus Borel, l'«individualité pivotale» du cénacle selon Gautier lui-même ${ }^{52}$, affirme péremptoirement dans la préface à son premier recueil poétique: «Oui, je suis républicain!» ${ }^{53}$. Par contre, dans le «Sonnet VII» Gautier, après avoir exprimé son aversion pour ce «siècle infâme» et la désillusion de la jeune génération à la suite de la révolution de Juillet, conclut dans le tercet final:

(48) En effet, le poète même affirme: «Cette immixtion de l'art dans la poésie a été et demeure un des signes caractéristiques de la nouvelle École, et fait comprendre pourquoi ses premiers adeptes se recrutèrent plutôt parmi les artistes que parmi les gens de lettres. Une foule d'objets, d'images, de comparaisons, qu'on croyait irréductibles au verbe, sont entrés dans le langage et y sont restés. La sphère de la littérature s'est élargie et renferme maintenant la sphère de l'art dans son orbe immense. Telle était la situation de nos esprits; les arts nous sollicitaient par les formes séduisantes qu'ils nous offraient pour réaliser notre rêve de beauté», Histoire du Romantisme cit., p. 72. Mais, en restant dans le cercle du Petit Cénacle, l'échange est réciproque. Pensons par exemple aux thèmes littéraires moyenâgeux prêtés à la sculpture comme dans le célèbre Roland furieux de Jehan du Seigneur exposé au salon de 1831 et considéré un chef-d'œuvre da la sculpture romantique; ou aux collaborations qui voient les artistes graver et illustrer les recueils des poètes comme par exemple pour les frontispices d'Albertus et des Jeunes-France de Gautier, de Rhapsodies de Pétrus Borel (deuxième édition de 1833) et de Feu et Flamme de Philothée O'Neddy (1833) gravés par Célestin Nanteuil.

(49) «Préface», Albertus cit., p. 83.

(50) Jasinski dans Les années romantique de Théophile Gautier à propos du Petit Cénacle et des sentiments qui l'animent parle de «deux grands principes étroitement liés: la libre expansion de l'individualité, le règne imprescriptible de l'art», op. cit., p. 76. Ces deux principes, le premier typiquement romantique, le second précurseur de l'art pour l'art, nous paraissent bien définir et résumer ce cercle qui en plein romantisme anticipe les tendances futures et le parcours de Gautier. Celui-ci dans Histoire du Romantisme rédige un ensemble de principes qui unissaient la jeune bande: «Déve- lopper librement tous les caprices de la pensée, dussent-ils choquer le goût, les convenances et les règles; haïr et repousser autant que possible ce qu'Horace appelait le profane vulgaire, et ce que les rapins moustachus et chevelus nomment épiciers, philistins ou bourgeois: célébrer l'amour avec un ardeur à brûler le papier, le poser comme seul but et seul moyen de bonheur, sanctifier et déifier l'Art regardé comme second créateur: telles sont les données du programme que chacun essaye de réaliser selon ses forces, l'idéal et les postulations secrètes de la jeunesse romantique», op. cit., p. 108.

(51) Dans la préface à son recueil Feu et Flamme, Philothée O'Neddy, en s'adressant à ses compagnons, écrit: «Comme vous, je méprise de toute la hauteur de mon âme l'ordre social et surtout l'ordre politique qui en est l'excrément $[\ldots]$ comme vous je n'ai de pieux élancements que vers la Poésie, cette sœur jumelle de Dieu», Paris, Librairie orientale de Dondey-Dupré, 1833, pp. VIII-IX. Et Joseph Bouchardy dans une lettre qu'il envoie à Gautier le 12 janvier 1857, et que Gautier reproduit dans son Histoire du Romantisme, rappelle: «Tandis que les fouriéristes faisaient des phalanstères, les saint-simoniens de nouveaux contrats sociaux, les démocrates des projets, sourds à tous ces bourdonnements d'alors nous n'entendions que le murmure de l'art qui s'agitait dans l'enfantement d'un progrès,... la plume, le pinceau, la lyre et le ciseau du statuaire était nos seules armes, les grands maîtres nos seuls dieux, et l'art le seul drapeau que nous voulions faire flotter et défendre», Correspondance générale, éditée par C. LACOSTE-VEYSSEYRE, tome VI, 1854-1857, Genève, Droz, 1991, pp. 272-273.

(52) Histoire du Romantisme cit., p. 73.

(53) Rhapsodies, Paris, Levavasseur, 1832, p. IX; affirmation à laquelle il ajoute que son républicanisme est de la «lycanthropie», affirmation qui lui vaudra le surnom de «lycanthrope». 
Seule la poésie incarnée en Hugo,

Ne nous a pas déçus, et de palmes divines

Vers l'avenir tournée ombrage nos ruines ${ }^{54}$.

La poésie est la seule raison de vie qui est restée, le seul espoir, mais aussi une solution pour s'évader de la réalité devenue ennuyeuse grâce à la «politique hargneuse» ${ }^{55}$ et dramatiquement dévastée par l'histoire; elle «ombrage» les «ruines», elle les recouvre, sans les éliminer pour autant, mais soustrayant aux yeux du poète cette vue morne, ténébreuse et effrayante. Ce dernier aspect est distinctif dans l'élaboration esthétique de Gautier et nous le reverrons à propos de la «consolation» apportée par les arts dans la dernière partie.

À ces déclarations se rattache une nouvelle sensibilité esthétique qui se répercutera sur la poésie de Gautier. Dans la préface, un aspect qui nous semble émerger par rapport à une certaine rhétorique du romantisme est d'abord le refus du sublime:

Un espace de quelques pieds où il fait moins froid qu'ailleurs, c'est pour lui l'univers. - Le manteau de la cheminée est son ciel; la plaque son horizon.

Il n'a vu du monde que ce que l'on en voit par la fenêtre, et il n'a pas eu envie d'en voir d'avantage ${ }^{56}$.

Si cette image représente métaphoriquement le repli du poète par rapport au monde et à la société, elle semble en même temps établir l'«horizon» thématique de sa poésie. L'univers entier se réduit à ce qui l'entoure: objets, formes, couleurs. Il veut limiter son regard, la profondeur de son regard, il n'a aucun intérêt pour autre chose ou plutôt son manque d'envie n'est que la peur d'être déçu par la réalité, ou de ne trouver rien d'autre que le vide, et il préfère donc se «distraire» par quelque chose de reconnu et de rassurant ${ }^{57}$. Le regard vers l'extérieur ne se réalise que par la fenêtre qui devient plutôt un écran limité et statique, un véritable tableau accroché sur le mur ${ }^{58}$. Rien de sublime, rien de grandiose, comme le dit Gautier lui-même dans la deuxième partie de la préface qui introduit plus spécifiquement les poèmes du volume: «l'auteur n'a pas eu la prétention de faire des monuments» ${ }^{59}$.

Si Gautier n'a pas voulu ici «construire» un monument, quelque chose de remarquable, d'apologétique ou d'élogieux, souvent excessivement rhétorique, le thème de la poésie comme construction architecturale sera dominant dans le recueil successif La Comédie de la Mort ${ }^{60}$. Pour l'instant le modèle de la poésie est la peinture. Un autre aspect qui se révèle donc dans la préface est l'association de la poésie aux arts plastiques. En effet pour décrire les poèmes qui suivent Gautier utilise des comparaisons picturales:

(54) Albertus cit., p. 113.

(55) «Préface», Albertus cit., p. 82

(56) «Préface», Albertus cit., p. 81.

(57) Comme dans la préface d'Albertus, nous trouvons également dans la préface aux Emaux et Camées l'opposition entre un dedans, le chezsoi, «fraîche oasis», lieu où le poète se retire et se consacre à l'art, et un dehors chaotique et bouleversé par la révolution, «l'ouragan», P.C., tome III, p. 3 .

(58) Le thème de la fenêtre comme emblème de l'art sera exploité par le parnassiens et les symbolistes; pensons aux vers de Mallarmé «Que la vitre soit l'art, soit la mysticité» dans son poème «Les fenêtres» recueilli dans le Parnasse contemporain de
1866, Genève, Slatkine reprints, 1971, p. 161.

(59) «Préface», Albertus, p. 83.

(60) Les poèmes qui encadrent le recueil son intitulés «Portail» et «Le sommet de la tour» et la construction d'une cathédrale devient la métaphore de son travail poétique. Le critique David $G$. BuRNETT a consacré plusieurs études à l'association architecture-poésie dans cette œuvre et dans la poésie de Gautier, cf. Sur la composition de "La Comédie de la mort”, «Bulletin de la Société Théophile Gautier», n. 2, 1980, L'architecture de la signification: Gautier et les visions architecturales romantiques, ibid., n. 4, 1982, Métaphore et signification architecturale dans les poésies de Théophile Gautier, ibid., n. 5, 1983. 
Ce sont d'abord de petits intérieurs d'un effet doux et calme, de petits paysages à la manière des Flamands, d'une touche tranquille, d'une couleur un peu étouffée, ni grandes montagnes, ni perspective à perte de vue, ni torrents, ni cataractes ${ }^{61}$.

D’un point de vue formel, le recueil présente plusieurs descriptions qui révèlent la tension qui sous-tend la création poétique de Gautier, c'est-à-dire la tentative de rendre des effets picturaux et plastiques par le moyen du vers. Le poète recherche un effet fortement visuel pour sa poésie, un caractère concret; il se fait «montreur» et la préface annonce les «transpositions d'art» typiques de la poétique gauterienne qui sont inaugurées dans le recueil ${ }^{62}$. Par exemple, Gautier qui, dans le poème «Paris» ${ }^{63}$, se définit «poète et peintre», cherche aussi à rendre les différents plans du paysage dans le poème «Point de vue» en imitant la profondeur de la perspective à travers trois mouvements du texte:

Au premier plan, - un orme au tronc couvert de mousse,

dans la brume hochant sa tête chauve et rousse;

[...]

Au second, - des moulins dressant leurs longues ailes,

$[\ldots]$

Puis, - tout au fond Paris, Paris sombre et fumeux ${ }^{64}$.

La lecture accompagne le regard imaginaire du lecteur dans ce paysage pittoresque à travers des comparaisons originelles, fort évocatrices et d'une étonnante netteté. On voit les arbustes «comme un pauvre la main, tendant leurs branches maigres». Les profils des moulins sont «comme un fil d'araignée à l'horizon brumeux». Mais surtout Paris avec «ses toits déchiquetés», ses «tours» et ses «clochers aigus» est «comme un peigne mordant la nue échevelée», comparaison qui arrête l'image de plus en plus étendue du paysage et la fixe en la réduisant à un objet quotidien et presque banal. Le «je» poétique est effacé au profit de la description du paysage ou de l'objet visés selon le précepte horatien, remis en honneur par les romantiques, ut pictura poesis. ${ }^{65}$.

Cependant, si l'admiration pour la peinture porte le poète à «créer» ses paysages poétiques c'est aussi toute une série d'objets vaguement artistiques qui suscitent l'admiration du poète et qu'il réclame comme source de bonheur:

Les bijoux curieusement ciselés, les colifichets rares, les parures singulières, sont des pures superfluités. - Qui voudrait cependant les retrancher? Le bonheur ne consiste pas à avoir ce qui est indispensable; ne pas souffrir n'est pas jouir, et les objets dont on a le moins besoin sont ceux qui charment le plus ${ }^{66}$.

Rétrospectivement, il est difficile de ne pas voir dans cette liste d'objets rares et précieux une anticipation du modèle esthétique auquel visera de plus en plus Gautier et qui fera du poète un véritable artisan du mot travaillant méthodiquement à la

(61) «Préface», Albertus cit., p. 83.

(62) En réalité, cette tendance est présente déjà dans son premier recueil Poésies et le poème «Paysage» en est un exemple, P.C., tome I, p. 6. La préface semble pourtant figer une sensibilité esthétique très précoce chez Gautier qui, comme nous l'avons annoncé, remonte en partie à sa formation initiale de peintre mais aussi au milieu artistique fréquenté.
(63) Ibid., p. 114.

(64) Ibid., p. 93.

(65) Dans Voyage en Espagne de 1843 Gautier se définira, dans une expression très moderne mais surtout très appropriée, «daguerréotype littéraire», édition présentée, établie et annotée par P. BERTHIER, Paris, Gallimard, Folio, 1981, p. 193.

(66) «Préface», Albertus cit., p. 83. 
manière d'un sculpteur ou d'un ciseleur une forme matérielle, et qui se manifestera ouvertement à partir du titre du recueil Émaux et Camées $^{67}$. Mais déjà dans ses premiers poèmes Gautier exploite pour les métaphores et les comparaisons tout un vocabulaire tiré des éléments minéraux: «albâtre», «corail», «nacre», «émail» ${ }^{68}$, «agate» ${ }^{69}$, «nacrée» ${ }^{70}$, «ivoire» ${ }^{71}$. L'aspect distinctif d'une nouvelle poétique caractérisée par l'aspiration à la matérialité et par la métaphore qui en dérive d'un poète qui travaille aussi «concrètement» qu'un peintre ou un sculpteur, surgit grâce à l'association que Gautier fait entre la poésie et l'ensemble des arts plastiques (peinture, architecture, sculpture et arts décoratifs). Elle se traduira de plus en plus dans le choix de sujets et d'images fortement évocatrices d'effets sensoriels et s'exprimera aussi par la préférence accordée à des formes poétiques bien déterminées ${ }^{72}$. Les intentions du poète sont de modifier à travers cette association, et les choix poétiques conséquents, le statut même de la poésie ${ }^{73}$.

Par ailleurs, au-delà de cet idéal de création c'est aussi la jouissance de l'objet artistique qui caractérise la conception esthétique de Gautier. Et la jouissance réclame souvent quelque chose de physique. Le culte de l'art et de la beauté n'est donc pas seulement un état d'extase mystique, une activité abstraite de l'esprit, mais également un plaisir sensible, concret, une volupté presque sensuelle, il s'agit de la delectatio qui est suscitée par la matérialité de l'art; rappelons que l'art «c'est la liberté, le luxe, l'efflorescence, c'est l'épanouissement de l'âme dans l'oisiveté». Dans le passage cité ci-dessus le poète parle explicitement de «jouir» et dans la préface à Mademoiselle de Maupin Gautier confirmera son désir d'assouvissement des plaisirs en disant que «la jouissance [lui] paraît le but de la vie, et la seule chose utile au monde» ${ }^{74}$.

(67) Dans son Rapport sur les progrès de la poésie française depuis 1830 Gautier écrira: «Ce titre, Émaux et Camées, exprime le dessin de traiter sous forme restreinte de petits sujets, tantôt sur plaque d'or ou de cuivre avec les vives couleurs de l'émail, tantôt avec la roue du graveur de pierres fines, sur l'agate, la cornaline ou l'onyx», contenu dans Rapport sur le progrès des lettres, Paris, Imprimerie impériale, 1868, p. 188.

(68) «Serment», Poésies, P.C., tome I, p. 12. Ce vocabulaire et ces images ressentent des descriptions exotiques coloriées et éprises de contrastes présentes dans les Orientales de Hugo. Mais chez Gautier l'évocation de la couleur passe à travers les comparaisons matérielles et ce procédé se développera dans l'audacieuse poétique des synesthésies et des correspondances qui aura son sommet dans Émaux et Camées.

(69) «Promenade nocturne», ibid., p. 29.

(70) «Sonnet IV», Albertus, p. 86.

(71) «Nonchaloir», ibid., p. 88.

(72) L'aspiration de Gautier à faire de la poésie un véritable «objet» artistique le portera à préférer les formes fixes comme par exemple le sonnet. En effet, Gautier appréciait beaucoup cette forme et il est un des grands interprètes de ce type de poème puisque le sonnet correspond à son idéal d'une beauté poétique plastique, voire géométrique, qui contraint le poète à «enchâsser» sa pensée dans une forme déterminée et difficile à «travailler»; dans son Rapport sur le progrès de la poésie il fait remonter l'usage du sonnet en époque romantique à Sainte-Beuve: «depuis lors cette forme charmante, taillée à facettes comme un flacon de cristal, et si merveilleusement propre à contenir une goutte de lumière ou d'essence, a été essayée par un grand nombre de poètes», p. 102 . Sur la portée de l'influence de Gautier en tant que «sonnettiste» cf. F.G. Henry, Théophile Gautier et l'avenir du sonnet, «Bulletin de la Société Théophile Gautier», n. 21, 1999, pp. 95-103. Mais Gautier est connu surtout pour son quatrain octosyllabique utilisé dans Émaux et Camées où chaque pièce est définie par Gautier lui-même comme «un médaillon à enchâsser sur le couvercle d'un coffret, un cachet à porter au doigt, serti dans une bague», Rapport sur le progrès de la poésie cit., p. 188. C'est bien le Gautier de ce recueil, d'un idéal de beauté éternelle, inspirée aussi par les modèles marmoréens classiques, d'une poésie considérée par la critique impassible et impersonnelle, d'une poésie «pour les yeux», qui sera admirée par les parnassiens.

(73) Dans le «Prospectus» que Gautier écrira au moment de son arrivée comme rédacteur en chef à la revue «L'Artiste», véritable tribune de l'art pour l'art, le poète affirme sur la poésie: «nous lui réserverons un escabeau d'ivoire, entre un tableau de maître et un groupe de marbre ou de bronze; nous la ferons asseoir dans un musée», «L'Artiste», 14 décembre 1856 , p. 1 . Autour de cet organe se grouperont aussi les premiers parnassiens et à ce propos nous renvoyons aux deux articles de P.J. EDWARD, Théophile Gautier rédacteur en chef de «L'Artiste», «Bulletin de la Société Théophile Gautier», n. 4, 1982 , et La revue «L'Artiste» et les poètes du Parnasse, «Bulletin des études parnassiennes», VIII, juin 1986, pp. 15-25.

(74) Mademoiselle de Maupin, Romans, contes et nouvelles, tome I, cit., p. 231. 
La présence d'un rapport sensoriel avec l'objet artistique qui acquiert un caractère sensuel, voire érotique, se transpose de manière évidente dans la personnification de la poésie en femme. Et si dans la préface cette femme-poésie semble plutôt innocente, puérile et chaste - «une poésie toute enfantine, toute ronde et potelée où les muscles ne se prononcent pas encore» ${ }^{75}$ - elle acquiert au cours du recueil des traits véritablement charnels, comme dans le poème «Débauche», particulièrement représentatif de cet aspect. Le poète à une «débauche prude» préfère une «débauche franche»:

Jetant son masque de satin,

Le coude sur la nappe et la main sur la hanche,

Criant, buvant jusqu'au matin,

Qui laisse, sans corset, aller sa gorge folle,

Rose encor des baisers du soir,

Qui tord lascivement sa taille souple et molle,

[...]

- C'est une poésie au moins, - une palette

Où brillent mille tons divers,

Un type net et franc, une chose complète,

De la couleur! des chants! des vers! $!^{16}$

L'affranchissement de la morale est légitimé par l'acte artistique: le vice même, ou ce qui est considéré comme tel par la bonne société, devient art. Mais l'artiste, dans sa prétendue supériorité, n'est pas seulement libre de choisir - encore qu'immoraux - ses sujets, il poursuit une nouvelle moralité à travers l'art, une moralité plus «franche», plus authentique ${ }^{77}$. Ici le culte de la beauté se teint d'hédonisme pour former cet esthétisme à la fois maniéré, excentrique et tourmenté, imprégné d'antirationalisme, que nous retrouverons dans l'esprit décadent fin de siècle et qui ne caractérise pas seulement la France des romans de Huysmans ou de certains tableaux de Gustave Moreau mais l'Europe entière. Il suffit de songer à Oscar Wilde et à son roman The Picture of Dorian Gray où la célèbre phrase de la préface «All art is quite useless» résonne des déclarations de Gautier, ou à certains aspects du contexte Sezessionstil viennois incarné par Gustave Klimt, en passant par Gabriele D’Annunzio et son roman Il piacere de 1889.

(75) «Préface», Albertus cit., p. 84.

(76) Ibid., p. 120.

(77) À ce propos, Carlo Pasi affirme: «Il vizio diventa simbolo di un'arte nuova, dalla vigoria e esuberanza giovanili, autonoma preziosa e temeraria. Ancora una volta si assiste in Gautier al passaggio dal dato fisico, vitale, alla dimensione estetica», Il sogno della materia cit., p. 92. Ce poème est intéressant pour la dénonciation tacite que fait Gautier d'une moralité fondamentalement hypocrite que le poète ne peut pas assumer dans sa vie et encore moins dans son art et qui sera au centre du «programme» poétique de Baudelaire, de son «projet radicalement réaliste» selon les mots de Mario Richter, au-delà de la dualité occidentale, du mal et du bien, cf. Les Fleurs du Mal, lecture intégrale, Genève, Slatkine, 2001. D'ailleurs, une révolution esthétique comporte aussi une révolution éthique comme l'observe Pierre Bourdieu: «Il est certain que, dans la phase héroïque de la conquête de l'autonomie, la rupture éthique est toujours, comme on le voit bien chez Baudelaire, une dimension fondamentale de toutes les ruptures esthétiques», op. cit., p. 106. Les procès intentés à Baudelaire et à Flaubert pour outrage à la morale publique en sont un exemple très clair. Dans la préface à Mademoiselle de Maupin Gautier déclarera que la morale est motif d'ennui: «Cette grande affection de morale qui règne maintenant serait fort risible si elle n'était fort ennuyeuse», op. cit., p. 212; et dans le roman, D'Albert, double de Gautier, confie à son ami: «Tu sais avec quelle ardeur j'ai recherché la beauté physique, quelle importance j'attache à la forme extérieure, et de quel amour je me suis pris pour le monde visible: - cela doit être, je suis trop corrompu et trop blasé pour croire à la beauté morale, et la poursuivre avec quelque suite. - J'ai perdu complètement la science du bien et du mal, et, à force de dépravation, je suis presque revenu à l'ignorance du sauvage et de l'enfant», p. 213. Il s'agit donc d'une morale primordiale, du sauvage et de l'enfant, plus vraie de celle qui est venue s'établir dans la société. 
L'inutilité de l'art revendiquée et presque orgueilleusement célébrée dans la préface d'Albertus cache pourtant un aspect qui n'est pas tout à fait secondaire et qui revalorise la conception de l'inutilité de l'art et donc de l'art même. En effet, à la fin de la préface Gautier déclare, sur un ton passant brusquement de l'assertion provocatrice qui traverse le texte à la constatation mélancolique, que l'art «est ce qui console le mieux de vivre» ${ }^{78}$. Il nous semble pourtant que la position finale et conclusive de cette qualité accordée à l'art lui fait acquérir une valeur prééminente.

Une consolation témoigne par définition d'un état de peine et de souffrance. La préface commence en effet par le portrait d'un poète annihilé, désœuvré, atteint par une condition de malaise: «L'auteur du présent livre est un jeune homme frileux et maladif $>^{79}$. Comme nous l'avons vu, il est retiré du monde, dans un lieu, sa maison, qui devient presque un cercueil symbolique (suggéré aussi par la litote du «moins froid qu'ailleurs» $\left.{ }^{80}\right)$. Il exprime des désirs à la limite d'un instinct suicide: «Il aime mieux être assis que debout, couché qu'assis. - C'est une habitude toute prise quand la mort vient nous coucher pour toujours ${ }^{81}$. Cependant, le poète, presque anéanti dans l'existence, conserve sa capacité artistique, sa créativité: «il fait des vers pour avoir un prétexte de ne rien faire, et ne fait rien sous prétexte qu'il fait des vers ${ }^{82}$. L'art devient donc le remède à cette condition de désarroi provoquée par une société vouée entièrement au progrès matériel ${ }^{83}$ et aux questions politiques et qui a relégué l'art à un rang inférieur, ou qui le considère seulement s'il est assujetti au pouvoir. Le concept d'inutilité se précise donc en relation à la subjectivité du poète. Si l'art est inutile dans le sens que nous avons vu, il est cependant utile au poète, son inutilité étant tout à fait relative:

Il y a et il y aura toujours des âmes artistes à qui les tableaux d'Ingres et de Delacroix, les aquarelles de Boulanger et de Decamps sembleront plus utiles que les chemins de fer et les bateaux à vapeur ${ }^{84}$.

Cette condition particulière d'utilité de l'art et de négation du progrès est reprise aussi dans la préface à Mademoiselle de Maupin où Gautier affirme que les sens du mot 'utilité' «n'est jamais que relatif» puisque pour le poète il est utile que son «premier vers rime avec [son] second ${ }^{85}$ et on ne peut pas prétendre une utilité dans les sens employé par les progressistes puisque «un roman n'est pas une paire de bottes sans couture; un sonnet, une seringue à jet continu; un drame n'est pas un chemin de fer $\gg^{86}$. Mais il ne s'agit pas simplement d'une utilité intrinsèque au domaine de l'art,

(78) «Préface», Albertus, p. 84.

(79) Ibid., p. 81.

(80) Voir ci-dessus note 54.

(81) Ibidem. On retrouve ces mêmes sentiments de nihilisme, mais encore plus extrémisés, aussi bien dans la préface à Jeunes-France que dans celle à Mademoiselle de Maupin. Dans la première Gautier déclare: «je ne suis rien, je ne fais rien; je ne vis pas, je végète; je ne suis pas un homme, je suis une huître», Romans, contes et nowvelles, tome I, cit., p. 19; dans la seconde il se demande: «y a-til quelque chose d'absolument utile sur cette terre et dans cette vie où nous sommes? D'abord il est très peu utile que nous soyons sur terre et que nous vivions», ibid., p. 229. Il est intéressant de constater qu'autour des années qui précèdent la rédaction de la préface Gautier exprime vraiment ces sentiments utilisant les mêmes termes dans un contexte qui ne présuppose pas un certain degré de fiction littéraire, c'est-à-dire dans sa correspondance privée où il écrit à Auguste Maquet: «Je vis de la manière la plus stupide, ou plutôt je ne vis pas, je végète», lettre datée 10 septembre 1830 , Correspondance générale cit., tome I, 1818-1842, 1985, p. 28.

(82) «Préface», Albertus cit., p. 81.

(83) «Enrichissez-vous!» c'est la formule attribuée au ministre Guizot devenue le symbole de la monarchie «bourgeoise» du roi Louis-Philippe après la révolution de 1830 .

(84) Albertus, «Préface» cit., p. 83.

(85) Mademoiselle de Maupin, Romans, contes et nouvelles, tome I, cit., p. 229; Gautier affirme aussi, de manière sarcastique, que le roman a deux utilités, dont l'une matérielle c'est-à-dire «les quelques mille francs qui entrent dans la poche de l'auteur», et une spirituelle puisque «pendant qu'on lit des romans, on dort, et on ne lit pas de journaux utiles, vertueux et progressifs, ou telles autres drogues indigestes et abrutissantes», p. 228.

(86) Ibid., pp. 227-228. 
de l'art poétique dans ce cas; l'art est absolument nécessaire au poète comme on le voit dans le célèbre passage reproduit ci-dessous, qui est considéré le commencement de l'art pour l'art, mais qui n'est autre chose qu'une continuation, une contextualisation et une amplification des idées ébauchées dans Albertus:

Il n'y a de vraiment beau que ce qui ne peut servir à rien: tout ce qui est utile est laid [...] Moi, n'en déplaise à ces messieurs, je suis de ceux pour qui le superflu est nécessaire ${ }^{87}$.

L'art est une consolation dans Albertus, il est nécessaire dans Mademoiselle de Maupin, l'art acquiert ainsi une fonction éminemment subjective. Il est inutile parce qu'il demeure indépendant des «choses de la vie» à cause de son statut de supériorité qui doit être préservé par l'artiste, mais il est aussi nécessaire grâce à la consolation qu'il apporte au poète à travers la création et la jouissance qu'il en tire. Cette consolation par l'art représente, nous semble-t-il, l'esprit de fond dominant qui caractérise la production poétique de Gautier, si vaste et diversifiée et à l'apparence si contradictoire. Ce n'est pas un hasard si Baudelaire dans l'article qu'il lui consacre en 1859 met en évidence, à côté du caractère mélancolique, cet aspect particulier du «poète impeccable» ${ }^{88}$, affirmé justement de manière explicite seulement dans la préface d'Albertus:

Théophile Gautier a continué d'un côté la grande école de la mélancolie créée par Chateaubriand. Sa mélancolie est même d'un caractère plus positif, plus charnel et confinant quelquefois à la tristesse antique. [...] D'un autre côté, il a introduit dans la poésie un élément nouveau, que j'appellerai la consolation par les arts, par tous les objets pittoresques qui réjouissent les yeux et amusent l'esprit ${ }^{89}$.

Création, contemplation et jouissance de l'art sont les seuls moyens d'échapper à la disparition et à la «mort» de l'artiste écrasé par la société. Si l'art inutile - par rapport aux catégories utilitaristes de la société bourgeoise - l'art pour la «Beauté», l'art pour l'art sont la condition pour sauvegarder l'art même, sa noblesse et sa supériorité, il est aussi «l'art pour l'artiste» puisqu'il assure son intégrité, son identité, voire sa véritable existence face à une réalité qui le refuse et qui le nie. Ce repli sur l'art entrepris par Gautier exprime ainsi une crise existentielle que le fait artistique essaie de résoudre.

(87) Ibid., p. 230.

(88) Célèbre appellation de la dédicace aux Fleurs du Mal.

(89) Charles BaudelaiRe, Théophile Gautier, première publication dans «L'Artiste» du 13 mars 1859. Nous citons d'après le texte contenu dans les Euvres complètes, Paris, Gallimard, «Bibliothèque de la Pléiade», tome II, 1976, texte établi, présenté et annoté par C. PICHOIs, p. 126. Baudelaire a-t-il lu la préface d'Albertus? C'est probable même si à l'époque c'était surtout le recueil des Poésies complètes, en plus des Émaux et Camées, qui avaient une discrète circulation témoignée par les deux rééditions de 1855 et 1858 . Ce volume en effet, publié par Charpentier en 1845 rassemblait toute la poésie de jeunesse de Gautier (Poésie de 1830, Albertus de 1832, La Comédie de la Mort de 1838 et les Poésies nouvelles comprenant Pièces diverses et España constitués par des poèmes épars et groupés en 1845) mais la préface d'Albertus avait été supprimée pour «diminuer la matière» de la publication selon Jasins- ki (P.C., p. vII) qui reprend Spoelberch de Lovenjoul (Histoire des CEuvres de Théophile Gautier, tome I, Paris, Charpentier, 1887, p. 1), mais nous ne savons pas sur quelle base objective. La préface sera rétablie dans l'édition des Poésies complètes éditées par Maurice DREYFous et publiées toujours par Charpentier dans deux volumes en 1875 et 1876 . On sait d'ailleurs que Baudelaire avait une prédilection surtout pour les recueils de jeunesse de Gautier (cf. C.M. SEnNinger, Baudelaire par Gautier, avec une étude de L.C. Hamrick, Paris, Klincksieck, 1986, p. 26) bien qu'il reconnaisse la qualité du recueil Emaux et Camées (cf. Ph.TerrIER, Charles Baudelaire, Théophile Gautier, deux études, «Études baudelairiennes», XI, Neuchâtel, La Baconnière, 1985, p. 115). Dans la première version de la dédicace aux Fleurs du Mal qu'il soumet à Gautier, Baudelaire cite en effet seulement les recueils précédents: «j'ai voulu, autant qu'il était en moi, en espérant mieux peut-être rendre un hommage profond à l'auteur d'Albertus, de La Comédie de la Mort et d'España, 
Dans Albertus, «la légende semi-diabolique, semi-fashionable» ${ }^{90}$, qui donne le titre au volume, nous retrouvons des éléments méta-poétiques - ou plutôt «métaartistiques»-qui prolongent les propos de la préface. Le protagoniste éponyme, véritable alter-ego de Gautier ${ }^{91}$, est un peintre esthète, un dandy, qui préfère l'art à la nature puisque la réalité le dégoûte: tout l'univers est pour lui un «tripot infâme» ${ }^{92}$. Et, à propos des intentions suicides voilées, le protagoniste est décrit comme «un cadavre sans illusion»» ${ }^{93}$. Tout le poème est une sorte d'allégorie qui thématise les idées sur l'art de Gautier ${ }^{94}$. Nous trouvons encore une fois exprimé par le poète, qui n'évite pas les incursions dans la narration, le concept de consolation par l'art:

Poésie, ô bel ange à l'auréole d'or,

[...]

Dans notre nuit suspends un moment ton essor,

Nous dis des mots tout bas, et du bout de ton aile

Sèches nos pleurs amers; - et toi sa sœur jumelle,

Peinture, la rivale et l'égale de Dieu,

Déception sublime, admirable imposture

Qui redonnes la vie et double la nature,

Je ne vous ai pas dit adieu!'5

Mais le protagoniste finit par succomber au culte de la beauté puisque il tombe amoureux d'une fille splendide qui en réalité est une sorcière déguisée à la suite d'un sortilège.

L'art est un repli pour l'artiste qui refuse la nature et la société ainsi données. Et celui qui va au fond de la réalité, comme l'a fait Albertus, ne voit que «boue infecte et noire»; la solution est pourtant de tourner le dos à la vie, de se consacrer à l'art et de masquer idéalement l'existence qui l'entoure:

- Jouissons, faisons-nous un bonheur de surface;

Un beau masque vaut mieux qu'une vilaine face.

- Pourquoi l'arracher, pauvres fous?"6

Si l'artiste rivalise donc avec Dieu, l'art pour Gautier n'est pas seulement une réalité dans la réalité, une création, et encore moins une mimesis, il est aussi une «déception», une «imposture», un masque qui recouvre cette «laideur» de la réalité comme la magie qui cache la véritable nature horrifique de la sorcière: l'art devient illusion ${ }^{97}$. D'ailleurs, une consolation n'extirpe jamais le problème à l'origine du mal.

au poète impeccable, au magicien ès langue française, dont je me déclare, avec autant d'orgueil que d'humilité, le plus dévoué, le plus respectueux et le plus jaloux des disciples», O.C., tome I, p. 187.

(90) «Préface», Albertus, p. 84.

(91) Jasinski affirme que par le titre Gautier a voulu rappeler le théologien du Moyen Âge Albert le Grand, Les années romantiques de Théophile Gautier cit., p. 103. Mais au-delà de la source d'inspiration du nom, plutôt incertaine, la similitude entre le protagoniste et Gautier et l'importance de l'œuvre pour le poète sont confirmées aussi par le fait que ce nom devint le surnom de Gautier comme l'affirme lui-même dans son autoportrait: «Le surnom d'Albertus me resta, et l'on ne m'appelait guère autrement dans ce qu'Alfred de Musset appelait: la grande boutique...romantique», Histoire du Romantisme cit., p. 441. Circonstance confirmée aussi par une lettre de Hugo datée le 11 avril 1845 où il s'adresse à Gautier en l'appelant Albertus, Correspondance générale cit., tome II, 1843. 1845,1986 , p. 233. Rappelons que dans son roman Mademoiselte de Maupin Gautier utilisera pour le protagoniste, encore une fois un double du poète, un nom semblable à celui d'Albertus: D'Albert.

(92) «Albertus», Albertus, p. 161.

(93) Ibid., p. 162.

(94) Cf. SAIDAH, art. cit., pp. 29-32, et C. GosSELIN SCHICK, "Albertus": Narrating Poetic Allegory, «French Literature Series», XVII, 1990, pp. 60-68.

(95) «Albertus», Albertus, p. 156.

(96) Ibid., p. 163.

(97) Jasinski définit Albertus «poème de l'illusion» qui «enseignerait l'oubli dans le mirage des apparences», Les années romantiques de Th. Gautier cit., p. 118. 
Par conséquent, se dédier à l'art n'est pas une solution réellement résolutive puisque en tant que consolation il ne peut que soulager le mal sans l'effacer, il est - il nous soit permis d'utiliser ce terme médical - un «palliatif»; et, en plus, parce que le rapport entre artiste et art, comme il se révèle dans Albertus, demeure conflictuel et dramatique: la création artistique existe en fonction d'un «Beau» qui est idéal et inaccessible ${ }^{98}$.

À la fin de ce parcours à travers la préface et quelques poèmes d'Albertus on peut tenter de tracer un bilan.

L'importance d'un certain climat pour la formulation de ce qui sera la doctrine de l'art pour l'art est indéniable mais cette préface révèle, au début de sa carrière littéraire, un jeune poète doté d'une forte indépendance et d'une riche originalité. Bien qu'il soit «initié» à la littérature sous l'égide de son maître Hugo, il s'en démarque bien tôt pour émerger aussi dans le cercle plus étroit de ses impétueux compagnons du Petit Cénacle. Sans attendre Mademoiselle de Maupin, déjà dans cette préface Gautier dépasse la simple profession de liberté de l'art pour atteindre une autonomie et une suprématie du fait artistique beaucoup plus avancées où seulement la poursuite de la «Beauté» acquiert une valeur prescriptive. Mais de quelle «Beauté»? Au risque de proposer une analyse trop téléologique, on peut affirmer que l'esthétique de la beauté concrète, mais en même temps, et paradoxalement, idéale, qui s'affinera au cours de l'évolution poétique de Gautier pour aboutir en toute sa perfection dans Émaux et Camées, est déjà ébauchée dans cette préface et dans le recueil, caractérisé par une constante référence aux beaux-arts, mais où en même temps l'aspiration au «Beau»-le «servir à être beau»-implique une dimension idéale et subjective. En effet, la consolation par les arts exprime et trahit cette subjectivité angoissée qui fait de l'art une idole (apparemment) salvatrice et du repli sur l'art son seul salut.

Nous retrouvons encore la condition de l'art comme remède à l'existence pénible du poète dans les œuvres successives: dans la Comédie de la Mort, l'art est conçue comme une barrière contre la mort et le néant, dans España la poésie devient l'oubli d'une réalité étouffante à travers l'évasion et le dépaysement symbolisés par le voyage", dans Émaux et Camées, finalement, l'idéal de «l'art robuste» rendu par la poétique formaliste et plasticienne des poèmes bijoux/sculptures devient le seul espoir d'accéder à l'éternité. Gautier, n'avait-il pas par ailleurs déjà exprimé dans une ode dédiée au sculpteur Jehan Duseigneur, publiée dans le Mercure de France en 1831 , le sentiment du temps qui passe inexorable et anéantit toutes choses?

Craignant le temps rongeur pour son œuvre fragile,

Le sculpteur veut changer son plâtre et son argile

À l'airain de Corinthe, au marbre de $\operatorname{Paros}^{100}$.

(98) La poursuite de cet idéal de beauté est orientée par ce que Baudelaire a appelé «Idée fixe» qui, chez Gautier, n'est que «l'amour exclusif du Beau», Théophile Gautier cit., p. 111. Baudelaire poussera aux extrêmes conséquences ce rapport conflictuel entre l'Art et l'artiste. En effet dans son poème «La Mort des artistes» la mort, l'«inconnu», est considérée comme le dernier espoir, la possibilité d'une nouvelle vie pour le poète-artiste qui «fera s'épanouir les fleurs de [son] cerveau». Â ce propos il est significatif que dans le poème la seule chose qui rivalise avec l'art et le dépasse en termes de Beauté idéale soit l'illusion de la beauté de la sorcière («Un poète amoureux n'aurait pas inventé | D'idéal plus parfait», p. 177). Le fait qu'Albertus ne puisse pas posséder complètement cette beauté parfaite, d'une part parce qu'elle est illusion et d'autre part parce qu'elle le conduit à la mort une fois qu'il aura possédé charnellement la belle sorcière - les deux aspects sont évidemment liés -, symbolise l'impossibilité de la part de l'artiste d'atteindre cet Idéal de beauté parfaite.

(99) Le poème liminaire du recueil «Départ» est une sorte de préface où se trouvent différentes idées de Gautier sur l'art: comme le «beau masque» d'Albertus dans ce poème Gautier parle du besoin qu'ont la réalité et sa «triste nudité», d'être couvertes par le «manteau» filé par l'imagination, España, P.C., tome II, p. 251.

(100) Ibid., tome III, p. 134. 
Voilà le marbre qui à côté de l'onyx e de l'émail, sera associé au vers dans le célèbre poème «L'Art» ${ }^{101}$ - le rapport entre le besoin de préservation du moi et l'aspiration à un art éternel est indissociable. Cette dimension ontologique évidente devrait faire évaluer l'œuvre du poète dans une perspective différente: sa poésie naît de l'état pénible et souffrant comme moyen pour préserver le «moi» poétique de la fracture qui demeure entre la société et le poète, mais aussi de la fracture qui traverse le «moi» du poète, lui-même brisé entre réalité et idéal.

Le refus du sublime dans la limite d'images qui reproduisent une beauté concrète, solide et immédiatement perceptible dans l'illusion de posséder et saisir cette beauté, semble répondre à la nécessité d'éviter l'effusion à l'aide d'un lyrisme par images qui fige les sentiments et surtout la dispersion du moi dans le vide ou dans l'évanescence d'une réalité en décomposition et destinée au néant; encore, il résout symboliquement la déchirure de ce moi brisé, le concentre et le recompose dans l'«objet» poétique pour aspirer à une beauté éternelle. À cet égard il nous paraît qu'il n'est pas conceptuellement impropre de corriger la formule de «l'art pour l'art» et d'utiliser pour Gautier la formule, employée ci-dessus, «l'art pour l'artiste». L'art de Gautier est tourné vers l'intérieur, vers l'individu, vers le sujet, et cet individualisme du rapport avec l'art se révèlera être le noyau central du subjectivisme moderne qui caractérisera l'art, mais aussi la société, et qui fera du relativisme, aussi bien dans la création que dans l'appréciation, par rapport aux systèmes consolidés, l'origine des «révolutions» esthétiques. Il nous semble que c'est dans cette perspective que la poésie de Gautier acquiert son sens le plus authentique au-delà des apparences ${ }^{102}$. En raison de cette interprétation on peut donc identifier une certaine cohérence qui fait reconduire l'objective hétérogénéité des recueils - caractérisés par une évolution continuelle, changements, innovations, revirements - à un système esthétique complexe qui demeure au-dessous de la création poétique spécifique et qui se manifeste, dans ses lignes fondamentales, à partir de cette préface.

Gautier assure une sorte de continuum entre le romantisme et les développements successifs et même si le caractère innovateur de la préface - qui ne présente pas le ton sentencieux typique d'une attitude programmatique - ne correspond pas à une claire, immédiate et totale innovation sur le plan proprement poétique ${ }^{103}$, elle anticipe pourtant un parcours qui sera entrepris par le poète et qui aura une vaste suite. Et il est curieux, en effet, de remarquer que dans la conclusion de sa préface Gautier, en parlant de ses poèmes, fait déjà preuve de chef de file:

Si ces études franches et consciencieuses peuvent ouvrir la voie à quelques jeunes gens et aider quelques inexpériences, l'auteur ne regrettera pas la peine qu'il a prise ${ }^{104}$.

(101) «Oui, l'œuvre sort plus bellelD'une forme au travaillRebelle,|Vers, marbres, onyx, émail». Mais rappelons que c'est le «rêve flottant» qui doit être scellé dans la matière: la poésie, l'art, naît toujours du travail entre idéalité et réel, immatérialité et matérialité, évanescence et caractère concret, P.C., tome III, cit., p. 130.

(102) Dans sa précieuse étude Théophile Gautier devant la critique qui, à travers un corpus de 500 articles, a le grand mérite de reconstituer l'origine des clichés et des stéréotypes qui ont empêché une pleine et profonde lecture de l'œuvre de Gautier, Aurélia Cervoni démontre à quel point la critique conteste dès le début une excessive attention du poète pour la forme au dépit du contenu idéologique qu'il soit politique, moral ou sentimental; thèse de doctorat, Université Paris-Sorbonne, 2011, cf. pp. 27-41. Nous remercions Aurélia Cervoni pour nous avoir donné la possibilité d'accéder à cette étude qui est en cours de publication.

(103) C'est pour cette raison que nous avons privilégié dans notre analyse surtout les poèmes qui manifestent une réflexion méta-poétique. D'ailleurs Gautier lui-même, dans son Rapport sur les progrès de la poésie, affirme qu'Albertus et le successif $\mathrm{La}$ Comédie de la Mort «rentrent dans le cycle carlovingien du romantisme», op. cit., p. 87.

(104) Albertus cit., p. 84. 
D'ailleurs toute une génération se référera non pas à la «leçon» de Hugo mais à celle de Gautier, notamment les parnassiens pour l'aspect formel et Baudelaire pour l'aspect le plus intime qu'on lui a souvent injustement nié ${ }^{105}$. Et Gautier lui-même en est tellement conscient que dans sa vieillesse il confessera aux Goncourt d'avoir «fait faire une bifurcation à l'école du romantisme, à l'école de la pâleur et des crevés...» ${ }^{106}$.

DAMIANO DE PIERI

(105) Les parnassiens s'attacheront plus au formalisme des Émaux et Camées, par contre Baudelaire saisira plutôt la condition existentielle exprimé dans Albertus et la Comédie de la Mort. Il faut se souvenir que l'insupportable réalité «d'aujourd'hui» dans le poème de Baudelaire «J'aime le souvenir de ces époques...» (Euvres complètes cit., tome I, p. 11) est gouvernée par le «dieu de l'Utile » de la culture bourgeoise. Cette réalité est en complète opposition aux «époques nues» dont Baudelaire aime le souvenir, époques caractérisées par un profond accord entre l'homme et la nature. Aussi bien pour Gautier que pour Baudelaire la poésie est nécessaire pour affronter le réel mais pour Baudelaire le simple refuge dans un idéal esthétique du passé, symbolisé par la marmoréenne éternité, comme le sera pour Gautier, n'est pas suffisant. D'ailleurs Rimbaud l'avait bien compris même s'il constate l'échec aussi de Baudelaire par rapport à sa tentative de devenir poète et de «se rendre voyant»: «Les seconds romantiques sont très voyants: Th. Gautier. Lec. de Lisle, Th. De Banville. Mais inspecter l'invisible et entendre l'inouï étant autre chose que reprendre l'esprit des choses mortes, Baudelaire est le premier voyant, roi des poètes, un vrai Dieu. Encore a-t-il vécu dans un milieu trop artiste; et la forme si vantée en lui est mesquine: les inventions d'inconnu réclament des formes nouvelles», «Lettre de Rimbaud à Paul Demeny», Charleville, 15 mai 1871, Euvres complètes, édition établie par A. GUYAUX avec la collaboration d'A. Cervoni, Paris, Gallimard, «Bibliothèque de la Pléiade», 2009, pp. 348.

(106) Journal des Goncourt, troisième volume, 1866-1870, cit., p. 43. 